\title{
Fixed points of generalized contraction mappings in vector metric spaces
}

\author{
Demet Binbasioglu \\ Department of Mathematics, Faculty of Arts and Science, Gaziosmanpaşa University, Tokat, Turkey
}

Received: 12 July 2018, Accepted: 31 July 2018

Published online: 29 October 2018.

\begin{abstract}
In this paper, we prove some theorems and a common fixed point theorem in vector metric spaces for generalized contraction mappings and give an example.
\end{abstract}

Keywords: Common fixed point, Riesz space, vector metric space.

\section{Introduction}

A vector metric space is generalization of metric space. This metric is Riesz space valued. A Riesz space is an ordered vector space and a lattice. Let $E$ be a Riesz space with the positive cone $E_{+}=\{x \in E: x \geq 0\}$. If $\left(a_{n}\right)$ is a decreasing sequence in $E$ such that $\inf a_{n}=a$, we write $a_{n} \downarrow a$. Actually, both vector metric and cone metric are vector space valued. One of the differences between definition of vector metric and definition of cone metric is that there exists a cone due to the natural existence of ordering on Riesz space. The other difference is that our definition eliminates the requirement for the vector space to have a topological structure.

Recently, many authors have studied on common fixed point theorems for weakly compatible pairs ([2],[3],[9]). Some of these works is gived in cone metric spaces ([1],[8],[9],[10],[11], [12]). Çevik and Altun ([4],[6]) prove Baire theorem and Banach fixed point theorem on vector spaces and give some theorems on point of coincidence and common fixed points for two self mappings satisfying some general contractive conditions in vector spaces. Generalized contraction mappings are matter of a lot of work in fixed point theory. Firstly, the mappings are defined in [5]. J. Gornicki and B. E. Rhoades obtain that common fixed point theorems using generalized contraction mappings ([7]).

In this paper, we prove some theorems and a common fixed point theorem in vector metric spaces for generalized contraction mappings and give an example.

\section{Preliminaries}

We shall require the following definitions in the sequel.

Definition 1. [6] The Riesz space $E$ is said to be Archimedean if $\frac{1}{n} a \downarrow 0$ holds for every $a \in E_{+}$.

Definition 2. [6] A sequence $\left(b_{n}\right)$ is said to order convergent (or $\circ-$ convergent) to $b$ if there is a sequence ( $\left.a_{n}\right)$ in $E$ satisfying $a_{n} \downarrow 0$ and $\left|b_{n}-b\right| \leq a_{n}$ for all $n$ and written $b_{n} \stackrel{\circ}{\longrightarrow} b$ or $\circ-\lim b_{n}=b$, where $|a|=\sup \{a,-a\}$ for any $a \in E$. 
Definition 3. [6] A sequence $\left(b_{n}\right)$ is said to be order-Cauchy (or o-Cauchy) if there exists a sequence $\left(a_{n}\right)$ in such that $a_{n} \downarrow 0$ and $\left|b_{n}-b_{n+p}\right| \leq a_{n}$ holds for all $n$ and $p$.

Definition 4. [6] The Riesz space E is said to be o-Cauchy complete if every o-Cauchy sequence is o-convergent.

Definition 5. [6] Let $X$ be a non-empty set and $E$ be a Riesz space. The function $d: X \times X \rightarrow E$ is said to be a vector metric (or E-metric) if it is satisfying the following properties:

(i) $d(x, y)=0$ if and only if $x=y$,

(ii) $d(x, y) \leq d(x, z)+d(y, z)$

for all $x, y, z \in X$. Also the triple $(X, d, E)$ is said to be vector metric space.

For arbitrary elements $x, y, z, w$ of a vector metric space, the following statements are satisfied.

(a) $0 \leq d(x, y)$;

(b) $d(x, y)=d(y, x)$;

(c) $|d(x, z)-d(y, z)| \leq d(x, y)$;

(d) $|d(x, z)-d(y, w)| \leq d(x, y)+d(z, w)$.

Definition 6. [6] A sequence $\left(x_{n}\right)$ in a vector metric space $(X, d, E)$ vectorial converges (or E-converges) to some $x \in E$, written $x_{n} \stackrel{d, E}{\rightarrow} x$, if there is a sequence $\left(a_{n}\right)$ in $E$ satisfying $a_{n} \downarrow 0$ and $d\left(x_{n}, x\right) \leq a_{n}$ for all $n$.

Definition 7. [6] A sequence $\left(x_{n}\right)$ is called E-Cauchy sequence whenever there exists a sequence $\left(a_{n}\right)$ in $E$ such that $a_{n} \downarrow 0$ and $d\left(x_{n}, x_{n+p}\right) \leq a_{n}$ holds for all $n$ and $p$.

Remark. [6] A vector metric space $X$ is called $E$-complete if each $E$-Cauchy sequence in $X, E$-converges to a limit in $X$.

There are the following properties;

If $x_{n} \stackrel{d, E}{\rightarrow} x$, then

$\left(i^{\prime}\right)$ The limit $x$ is unique,

(ii') Every subsequence of $\left(x_{n}\right) E$-converges to $x$,

$($ iii $)$ If also $y_{n} \stackrel{d, E}{\rightarrow} y$, then $d\left(x_{n}, y_{n}\right) \stackrel{\circ}{\rightarrow} d(x, y)$.

When $E=\mathbb{R}$, the concepts of vectorial convergence and convergence in metric are the same. When also $X=E$ and $d$ is the concepts of absolute valued vector metric, vectorial convergence and convergence in order are the same. When $E=\mathbb{R}$, the concepts of $E$-Cauchy sequence and Cauchy sequence are the same.

Remark. [6] It is well known that $\mathbb{R}^{2}$ is a Riesz space with coordinatwise ordering defined by $\left(x_{1}, y_{1}\right) \leq\left(x_{2}, y_{2}\right) \Leftrightarrow$ $x_{1} \leq x_{2}$ and $y_{1} \leq y_{2}$ for $\left(x_{1}, y_{1}\right),\left(x_{2}, y_{2}\right) \in \mathbb{R}^{2}$. Again $\mathbb{R}^{2}$ is a Riesz space with lexicographical ordering defined by $\left(x_{1}, y_{1}\right) \leq\left(x_{2}, y_{2}\right) \Leftrightarrow x_{1}<x_{2}$ or $x_{1}=x_{2}, y_{1} \leq y_{2}$. Note that $\mathbb{R}^{2}$ is Archimedean with coordinatwise ordering but not with lexicographical ordering.

Remark. [6] If $E$ is a Riesz space and $a \leq k a$ where $a \in E_{+}, k \in[0,1)$, then $a=0$.

Definition 8. [12] Let $S$ be a non-empty set and let $\left\{T_{\alpha}\right\}_{\alpha \in J}$ be a family of self mappings on $S$ and $J$ an indexing set. A point $u \in S$ is called a common fixed point for a family $\left\{T_{\alpha}\right\}_{\alpha \in J}$ if and only if $u=T_{\alpha} u$ for each $T_{\alpha}$. 


\section{Main results}

Theorem 1. Let $X$ be an E-complete vector metric space with $E$ is Archimedean. Suppose the mapping $T: X \rightarrow X$ satisfies the following condition for all $x, y \in X$ and a constant $\alpha \in\left[0, \frac{1}{2}\right)$

$$
d(T(x), T(y)) \leq \alpha(d(T(x), x)+d(T(y), y))
$$

Then $T$ has a unique fixed point in $X$ and for any $x \in X$, the iterative sequence $T^{n} x$ converges to the fixed point.

Proof. Let we take $x_{0} \in X$. Define the sequence $\left(x_{n}\right)$ by $x_{1}=T\left(x_{0}\right), x_{2}=T\left(x_{1}\right)=T^{2} x_{0}, \ldots, x_{n+1}=T\left(x_{n}\right)=T^{n+1} x_{0}, \ldots$ Then we have

$$
d\left(x_{n+1}, x_{n}\right)=d\left(T x_{n}, T x_{n-1}\right) \leq \alpha\left(d\left(T x_{n}, x_{n}\right)+d\left(T x_{n-1}, x_{n-1}\right)\right)=\alpha\left(d\left(x_{n+1}, x_{n}\right)+d\left(x_{n}, x_{n-1}\right)\right) .
$$

So $d\left(x_{n+1}, x_{n}\right) \leq \frac{\alpha}{1-\alpha} d\left(x_{n}, x_{n-1}\right)$ where $\beta=\frac{\alpha}{1-\alpha}$. For $\mathrm{n}, \mathrm{m}$

$$
d\left(x_{n}, x_{m}\right) \leq d\left(x_{n}, x_{n-1}\right)+d\left(x_{n-1}, x_{n-2}\right)+\cdots+d\left(x_{m+1}, x_{m}\right) \leq\left(\beta^{n-1}+\beta^{n-2}+\cdots+\beta^{m}\right) d\left(x_{1}, x_{0}\right) \leq \frac{\beta^{m}}{1-\beta} d\left(x_{1}, x_{0}\right) .
$$

Now since $E$ is Archimedean then $\left(x_{n}\right)$ is an $E$-Cauchy. By the $E$-completeness of $X$, there is $z \in X$ such that $x_{n} \stackrel{d, E}{\rightarrow} z$. Hence there exists $\left(a_{n}\right)$ in $E$ such that $\left(a_{n}\right) \downarrow 0$ and $d\left(x_{n}, z\right) \leq a_{n}$. Now we show that $z$ is a fixed point of $T$.

$$
d(T z, z) \leq d\left(T x_{n}, T z\right)+d\left(T x_{n}, z\right) \leq \alpha\left(d\left(T x_{n}, x_{n}\right)+d(T z, z)\right)+d\left(x_{n+1}, z\right)
$$

then $d(T z, z) \leq \frac{\alpha}{1-\alpha}\left(d\left(T x_{n}, x_{n}\right)+d\left(x_{n+1}, z\right)\right)$. This implies $T z=z$. So $z$ is a fixed point of $T$. Now we take $w$ is another fixed point of $T$, then $d(z, w)=d(T z, T w) \leq \alpha(d(T z, z)+d(T w, w))=0$. Thus $z=w$. Therefore the fixed point of $T$ is unique.

Remark. The Banach contraction mappings are known to be continuous. But generalized contraction mappings are not continuous, generally. The following example was given in complete metric spaces which are $E$-complete vector metric spaces. As a result, it can be said that the Kannan's mappings are not necessarily continuous.

Example 1. Let $E=\mathbb{R}^{2}$ with coordinatwise ordering (since $\mathbb{R}^{2}$ is not Archimedean with Lexicographical ordering, then we can not use this ordering) and $X=[0,3]$ be the set of real numbers with the metric $d(x, y)=k|x-y|, l|x-y|)$, $k, l>0$. Define $T: X \rightarrow X$ by

$$
T(x)=\left\{\begin{array}{l}
\frac{x}{5}, \quad \text { if } \mathrm{x} \leq 2 \\
\frac{x}{3}, \text { if } 2<x \leq 3
\end{array}\right.
$$

For $x, y \in[0,2]$ we have

$$
d(T x, T y)=(k|T x-T y|, l|T x-T y|)=\left(k\left|\frac{x}{5}-\frac{y}{5}\right|, l\left|\frac{x}{5}-\frac{y}{5}\right|\right)=\left(\frac{k}{5}|x-y|, \frac{l}{5}|x-y|\right) .
$$

$k>0$ and $l>0$, so $\frac{k}{5}>0$ and $\frac{l}{5}>0$. Hence

$$
\begin{aligned}
d(T x, T y) & =\left(\frac{k}{5}|x-T x+T x-T y+T y|, \frac{l}{5}|x-T x+T x-T y+T y|\right) \\
& \leq\left(\frac{k}{5}|x-T x|+\frac{k}{5}|T x-T y|+\frac{k}{5}|T y-y|, \frac{l}{5}|x-T x|+\frac{l}{5}|T x-T y|+\frac{l}{5}|T y-y|\right) \\
& \leq \frac{1}{5}[d(x, T x)+d(T x, T y)+d(y, T y)] .
\end{aligned}
$$


Thus $d(T x, T y) \leq \frac{1}{4}[d(x, T x)+d(y, T y)]$ then $d(T x, T y) \leq \frac{1}{2}[d(x, T x)+d(y, T y)]$.

Similarly we get that the same inequality holds for other cases of $x, y$. But $T$ is not continuous.

Theorem 2. Let $X$ be an E-complete vector metric space with $E$ is Archimedean. Suppose the mapping $T: X \rightarrow X$ satisfies the following condition for all $x, y \in X$

$$
d(T(x), T(y)) \leq k(x, y) d(x, y)+l(x, y) d(x, T x)+m(x, y) d(y, T y)+n(x, y)[d(x, T y)+d((y, T x)] .
$$

Here take $k, l, m, n: X \times X \rightarrow[0,1)$ are functions such that

$$
\alpha=\sup \{k(x, y)+l(x, y)+m(x, y)+2 n(x, y): x, y \in X\}<1
$$

then

(a) Thas a unique fixed point

(b) $T^{n} x \stackrel{d, E}{\rightarrow}$ u as $n \rightarrow \infty$, for each $x \in X$

(c) $d\left(T^{n} x, u\right) \leq \frac{\alpha^{n}}{1-\alpha} d(x, T x)$.

Proof. Let we take $x \in X$. Define the sequence $\left(x_{n}\right)$ by $x_{0}=x, x_{1}=T x_{0}, x_{2}=T x_{1}, \ldots, x_{n+1}=T x_{n}, \ldots$. From 1 ,

$$
\begin{aligned}
d\left(x_{n}, x_{n+1}\right)=d\left(T x_{n-1}, T x_{n}\right) & \leq k\left(x_{n-1}, x_{n}\right) d\left(x_{n-1}, x_{n}\right)+l\left(x_{n-1}, x_{n}\right) d\left(x_{n-1}, x_{n}\right) \\
& +m\left(x_{n-1}, x_{n}\right) d\left(x_{n}, x_{n+1}\right)+n\left(x_{n-1}, x_{n}\right)\left[d\left(x_{n-1}, x_{n+1}\right)+d\left(x_{n}, x_{n}\right)\right]
\end{aligned}
$$

or

$$
\begin{aligned}
d\left(x_{n}, x_{n+1}\right)=d\left(T x_{n-1}, T x_{n}\right) & \leq k\left(x_{n-1}, x_{n}\right) d\left(x_{n-1}, x_{n}\right)+l\left(x_{n-1}, x_{n}\right) d\left(x_{n-1}, x_{n}\right) \\
& +m\left(x_{n-1}, x_{n}\right) d\left(x_{n}, x_{n+1}\right)+n\left(x_{n-1}, x_{n}\right) d\left(x_{n-1}, x_{n+1}\right) .
\end{aligned}
$$

By the triangle inequality, we obtain that

$$
d\left(x_{n-1}, x_{n+1}\right) \leq d\left(x_{n-1}, x_{n}\right)+d\left(x_{n}, x_{n+1}\right)
$$

Therefore,

$$
d\left(x_{n}, x_{n+1}\right) \leq d\left(x_{n-1}, x_{n}\right)+d\left(x_{n}, x_{n+1}\right) \leq 2 \max \left\{d\left(x_{n-1}, x_{n}\right), d\left(x_{n}, x_{n+1}\right)\right\} .
$$

From 3 and 4.

$$
d\left(x_{n}, x_{n+1}\right) \leq(k+l+m) \max \left\{d\left(x_{n-1}, x_{n}\right), d\left(x_{n}, x_{n+1}\right)\right\}+2 n \max \left\{d\left(x_{n-1}, x_{n}\right), d\left(x_{n}, x_{n+1}\right)\right\}
$$

Then

$$
d\left(x_{n}, x_{n+1}\right) \leq \alpha \max \left\{d\left(x_{n-1}, x_{n}\right)+d\left(x_{n}, x_{n+1}\right)\right\}
$$

Since $\alpha<1$, then

$$
d\left(x_{n}, x_{n+1}\right) \leq \alpha d\left(x_{n-1}, x_{n}\right)
$$

By inductivity, we get

$$
d\left(x_{n}, x_{n+1}\right) \leq \alpha d\left(x_{n-1}, x_{n}\right) \leq \alpha . \alpha d\left(x_{n-2}, x_{n-1}\right) \leq \cdots \leq \alpha^{n} d(x, T x) .
$$


Since a vector metric has triangle inequality, for $m>n$ we obtain

$$
d\left(x_{n}, x_{m}\right) \leq d\left(x_{n}, x_{n+1}\right)+d\left(x_{n+1}, x_{n+2}\right)+\ldots+d\left(x_{m-1}, x_{m}\right) .
$$

From 7

$$
\begin{aligned}
d\left(x_{n}, x_{m}\right) & \leq d\left(x_{n}, x_{n+1}\right)+d\left(x_{n+1}, x_{n+2}\right)+\ldots+d\left(x_{m-1}, x_{m}\right) \\
& \leq \alpha^{n} d(x, T x)+\alpha^{n+1} d(x, T x)+\ldots+\alpha^{m-1} d(x, T x) \\
& \leq \frac{\alpha^{n}}{1-\alpha} d(x, T x) .
\end{aligned}
$$

Now since $E$ is Archimedean then $\left(x_{n}\right)$ is an $E$-Cauchy. By the $E$-completeness of $X$, there is $z \in X$ such that $x_{n} \stackrel{d, E}{\rightarrow} z$. Hence there exists $\left(a_{n}\right)$ in $E$ such that $\left(a_{n}\right) \downarrow 0$ and $d\left(x_{n}, z\right) \leq a_{n}$.

Now we show that $z$ is a fixed point of $T$. From 1 and 2

$$
\begin{aligned}
d\left(T z, T x_{n}\right) & \leq k\left(z, x_{n}\right) d\left(z, x_{n}\right)+l\left(z, x_{n}\right) d(z, T z)+m\left(z, x_{n}\right) d\left(x_{n}, T x_{n}\right)+n\left(z, x_{n}\right)\left[d\left(z, T x_{n}\right)+d\left(x_{n}, T z\right)\right] \\
& \leq\left[k\left(z, x_{n}\right)+l\left(z, x_{n}\right)+m\left(z, x_{n}\right)+2 l\left(z, x_{n}\right)\right] \max \left\{d\left(z, x_{n}\right), d(z, T z), d\left(x_{n}, x_{n+1}\right), d\left(z, x_{n+1}\right), d\left(x_{n}, T z\right)\right\} \\
& \leq \alpha \max \left\{d\left(z, x_{n}\right), d(z, T z), d\left(x_{n}, x_{n+1}\right), d\left(z, x_{n+1}\right), d\left(x_{n}, T z\right)\right\} .
\end{aligned}
$$

Then we obtain $d(T z, z) \leq \alpha d(z, T z)$. Since $\alpha<1$, then $d(T z, z)=0$ and hence $T z=z$.

Now, let we show uniqueness. Assume $x, y \in X$ and $x \neq y$ are two fixed points of $T$. From 1, then

$$
\begin{aligned}
d(x, y) & =d(T x, T y) \\
& \leq k(x, y) d(x, y)+l(x, y) d(x, T x)+m(x, y) d(y, T y)+n(x, y)[d(x, T y)+d(y, T x)] \\
& \leq[k(x, y)+2 n(x, y)] d(x, y) \\
& \leq \alpha d(x, y),
\end{aligned}
$$

since $\alpha<1$, then $d(x, y)=0$ so $x=y$. Since $x \in X$ was arbitrary, then for $a_{n} \downarrow 0, d\left(x_{n}, z\right) \leq a_{n}$ we conclude that $(b)$ holds.

To show $(c)$ taking $d\left(x_{n}, x_{m}\right) \leq \frac{\alpha^{n}}{1-\alpha} d(x, T x)$ as $m \rightarrow \infty$ and making use of Lemma 1, we obtain $d\left(T^{n} x, u\right) \leq \frac{\alpha^{n}}{1-\alpha} d(x, T x)$ for all $n$.

Proposition 1. $T$ is a generalized contraction mapping on a E-complete vector metric space satisfying

$$
d(T x, T y) \leq \alpha \max \left\{d(x, y), d(x, T x), d(y, T y), \frac{1}{2}[d(x, T y)+d(y, T x)]\right\}
$$

where $\alpha \in(0,1)$ and $x, y \in X$. Then T has a unique fixed point and at this point it is continuous.

Proof. From above theorem we know that $T$ has a unique fixed point. Let we take $z \in X$ and $\left\{y_{n}\right\} \subseteq X$, be such that $y_{n} \stackrel{d, E}{\rightarrow} z$. Hence there exists $\left(a_{n}\right)$ in $E$ such that $a_{n} \downarrow 0$ and $d\left(y_{n}, z\right) \leq a_{n}$. From 1, we have

$$
d\left(T y_{n}, T z\right) \leq \alpha \max \left\{d\left(y_{n}, z\right), d\left(y_{n}, T y_{n}\right), d(y, T y), \frac{1}{2}\left[d\left(y_{n}, z\right)+d\left(z, T y_{n}\right)\right]\right\} \leq \alpha d\left(y_{n}, z\right)+\alpha d\left(T z, T y_{n}\right)
$$


or

$$
\begin{aligned}
d\left(T y_{n}, T z\right)-\alpha d\left(T z, T y_{n}\right) & \leq \alpha d\left(y_{n}, z\right) \Rightarrow(1-\alpha) d\left(T z, T y_{n}\right) \leq \alpha d\left(y_{n}, z\right) \\
& \Rightarrow d\left(T z, T y_{n}\right) \leq \frac{\alpha}{(1-\alpha)} d\left(y_{n}, z\right) \leq \frac{\alpha}{1-\alpha} a_{n}
\end{aligned}
$$

From 8 and above Remark then $T y_{n} \stackrel{d, E}{\rightarrow} T z$. Thus $T$ is continuous at a fixed point.

Theorem 3. Let $X$ be an $E$-complete vector metric space with $E$ is Archimedean and $\left\{T_{i}\right\}_{i \in J}$ is a family of self mappings of $X$. If there exists a fixed $j \in J$ such that for each $\alpha \in J$, there exists a fixed $j \in J$, for some $\alpha=\alpha(i) \in(0,1)$ and all $x, y \in X$, we have

$$
d\left(T_{i} x, T_{j} y\right) \leq \alpha \max \left\{d(x, y), d\left(x, T_{i} x\right), d\left(y, T_{j} y\right), \frac{1}{2}\left[d\left(x, T_{j} y\right)+d\left(y, T_{i} x\right)\right]\right\} \cdots
$$

Then all $T_{i}$ have a unique common fixed point, which is a unique fixed point of each $T_{i}, i \in J$.

Proof. Let we take $i \in J$ and $x \in X$. Define the sequence $\left(x_{n}\right)$ by $x_{0}=x, x_{2 n+1}=T_{i} x_{2 n}, x_{2 n+2}=T_{i} x_{2 n+1}, n \geq 0$. From 7 ,

$$
\begin{aligned}
d\left(x_{2 n+1}, x_{2 n+2}\right) & =d\left(T_{i} x_{2 n}, T_{j} x_{2 n+1}\right) \\
& \leq \alpha \max \left\{d\left(x_{2 n}, x_{2 n+1}\right), d\left(x_{2 n}, x_{2 n+1}\right), d\left(x_{2 n+1}, x_{2 n+2}\right), \quad \frac{1}{2}\left[d\left(x_{n}, x_{2 n+2}\right)+d\left(x_{2 n+1}, x_{2 n+1}\right)\right]\right\}
\end{aligned}
$$

Since $d\left(x_{2 n}, x_{2 n+2}\right) \leq d\left(x_{2 n}, x_{2 n+1}\right)+d\left(x_{2 n+1}, x_{2 n+2}\right)$. Then

$$
\frac{1}{2} d\left(x_{2 n}, x_{2 n+2}\right) \leq \frac{1}{2}\left[d\left(x_{2 n}, x_{2 n+1}\right)+d\left(x_{2 n+1}, x_{2 n+2}\right)\right] \leq \max \left\{d\left(x_{2 n}, x_{2 n+1}\right), d\left(x_{2 n+1}, x_{2 n+2}\right)\right\}
$$

we have $d\left(x_{2 n+1}, x_{2 n+2}\right) \leq \alpha \max \left\{d\left(x_{2 n}, x_{2 n+1}\right), d\left(x_{2 n+1}, x_{2 n+2}\right)\right\}$. Hence as $\alpha<1, d\left(x_{2 n+1}, x_{2 n+2}\right) \leq \alpha d\left(x_{2 n}, x_{2 n+1}\right)$.

Similarly, we obtain that $d\left(x_{2 n}, x_{2 n+1}\right) \leq \alpha d\left(x_{2 n-1}, x_{2 n}\right)$. For any $n \geq 1$,

$$
d\left(x_{n}, x_{n+1}\right) \leq \alpha d\left(x_{n-1}, x_{n}\right) \leq \alpha^{2} d\left(x_{n-2}, x_{n-1}\right) \leq \cdots \leq \alpha^{n} d\left(x_{0}, x_{1}\right)
$$

Thus from 1 and since a vector metric has triangle inequality for $m>n$ we obtain

$$
\begin{aligned}
d\left(x_{n}, x_{m}\right) & \leq d\left(x_{n}, x_{n+1}\right)+d\left(x_{n+1}, x_{n+2}\right)+\cdots+d\left(x_{m-1}, x_{m}\right) \leq \alpha^{n} d\left(x_{0}, x_{1}\right)+\alpha^{n+1} d\left(x_{0}, x_{1}\right)+\cdots+\alpha^{m-1} d\left(x_{0}, x_{1}\right) \\
& \leq\left(\alpha^{n}+\alpha^{n+1}+\cdots+\alpha^{m-1}\right) d\left(x_{0}, x_{1}\right) \leq \frac{\alpha^{n}}{1-\alpha} d\left(x_{0}, x_{1}\right) .
\end{aligned}
$$

Now since $E$ is Archimedean then $\left(x_{n}\right)$ is an $E$-Cauchy. By the $E$-completeness of $X$, there is $z \in X$ such that $x_{n} \stackrel{d, E}{\rightarrow} z$. Hence there exists $\left(a_{n}\right)$ in $E$ such that $a_{n} \downarrow 0$ and $d\left(x_{n}, z\right) \leq a_{n}$. From (vii), we get

$$
d\left(T_{j} z, x_{2 n+1}\right)=d\left(T_{j} z, T_{i} x_{2 n}\right) \leq \alpha \max \left\{d\left(z, x_{2 n}\right), d\left(z, T_{j} z\right), d\left(x_{2 n}, x_{2 n+1}\right), \frac{1}{2}\left[d\left(z, x_{2 n+1}\right)+d\left(x_{2 n}, T_{j} z\right)\right]\right\}
$$

By $(x)$ and Lemma 1 we obtain $d\left(T_{j} z, z\right) \leq \alpha d\left(z, T_{j} z\right)$. Therefore, $d\left(T_{j} z, z\right)=0$ and so $T_{j} z=z$. Now, we prove that $z$ is a fixed point of all $\left\{T_{i}\right\}_{i \in J}$, let $i \in J$ be arbitrary. Then from 6 with $x=y=z=T_{j} z$ we have

$$
d\left(z, T_{i} z\right)=d\left(T_{j} z, T_{i} z\right) \leq \alpha(i) \max \left\{d\left(z, T_{i} z\right), \frac{1}{2} d\left(z, T_{i} z\right)\right\}
$$

and so $T_{i} z=z$. Therefore all $T_{i}$ have a common fixed point. 
For uniqueness we suppose that $w$ is another fixed point of $T_{j}$. Then $w$ is a common fixed point of all $\left\{T_{i}\right\}_{i \in J}$. Thus from $7, d(z, w)=d\left(T_{j} z, T_{i} w\right) \leq \alpha d(z, w)$ and $w=z$. Hence $z$ is a unique common fixed point of all $\left\{T_{i}\right\}_{i \in J}$.

\section{Competing interests}

The authors declare that they have no competing interests.

\section{Authors' contributions}

All authors have contributed to all parts of the article. All authors read and approved the final manuscript.

\section{References}

[1] M. Abbas, G. Jungck, Common fixed point results for non-commuting mappings without continuity in cone metric spaces, J. Math. Anal. Appl., 341 (2008), 416-420.

[2] I. Altun, D. Turkoglu, Some fixed point theorems for weakly compatible mappings satisfying an implicit relation, Taiwanese J. Math., 13 (4) (2009), 1291-1304.

[3] I. Altun, D. Turkoglu, B.E. Rhoades, Fixed points of weakly compatible maps satisfying a general contractive condition of integral type, Fixed Point Theory Appl., 2007, Art. ID 17301, 9 pp.

[4] I. Altun and C. Çevik, Some common fixed point theorems in vector metric spaces, Filomat, 25:1 (2011), 105-113.

[5] Lj. B. Ciric, Generalized contractions and fixed point theorems, Publ. Inst. Math. 12(1971),19-26.

[6] C. Çevik, I. Altun, Vector metric spaces and some properties, Topol. Met. Nonlin. Anal., 34 (2) (2009), 375-382.

[7] J. Gornicki, B. E. Rhoades, A general fixed point theorem for involutions, Indian J. Pure. Appl. Math. 27(1996), 13-23.

[8] L.-G. Huang, X. Zhang, Cone metric spaces and fixed point theorems of contractive mappings, J. Math. Anal. Appl., 332 (2007), 1468-1476.

[9] G. Jungck, S. Radenović, S. Radojević, V. Rakočević, Common fixed point theorems for weakly compatible pairs on cone metric spaces, Fixed Point Theory Appl., 2009, Art. ID 643840, 13 pp.

[10] S. Radenović, V. Rakočević, S. Resapour, Common fixed points for (g, f) type maps in cone metric spaces, Applied Mathematics and Computation, 218 (2011) 480-491.

[11] Sh. Rezapour, R. H. Haghi, Fixed point of multifunctions on cone metric spaces, Numer. Funct. Anal. Optim. 30(2009), 825-832.

[12] D. Turkoglu, M. Abuloha and T. Abdeljawad, Fixed points of generalized contraction mappings in cone metric spaces, Mathematical Communications, 16 (2011), 325-334. 